\title{
SOURCE PARAMETERS OF THE 1957 ALEUTIAN EARTHQUAKE FROM TSUNAMI WAVEFORMS
}

\author{
Jean M. Johnson and Kenji Satake \\ Department of Geological Sciences, The University of Michigan
}

\begin{abstract}
We studied the source parameters of the 1957 Aleutian earthquake using tsunami waveform data recorded on tide gauges around the Pacific Ocean. Using a finitedifference computation, this tsunami can be numerically simulated. The tsunami records were inverted for the slip distribution on the rupture area. Results show that slip was concentrated in the western half of the aftershock zone with a maximum displacement of $7 \mathrm{~m}$. The moment computed from the slip distribution is $88 \times 10^{20} \mathrm{Nm}$, giving the 1957 earthquake a moment magnitude of $M_{w}=8.6$. The waveform inversion confirms that no slip occurred in the Unalaska Island area, making this area a possible seismic gap with a potential to rupture in a great earthquake and generate a Pacific-wide tsunami.
\end{abstract}

\section{Introduction}

The Alaska-Aleutian Arc has a history of repeatedly rupturing in great earthquakes. The most recent sequence, in the past 55 years, has ruptured almost the entire arc from southern Alaska to the western Aleutians. However, some segments of the arc have apparently not ruptured during this sequence, and these areas are called seismic gaps. These gaps are delineated by the ends of the rupture zones of the adjacent great earthquakes; therefore, it is important to know the bounds of rupture of the great events.

Among the recent large earthquakes, the 1957 Aleutian earthquake ( 9 March 1957 at 14:22 GMT, epicenter $51.63^{\circ} \mathrm{N}$, $175.41^{\circ} \mathrm{W}, \mathrm{M}_{\mathrm{S}}=8.1$ ) has been least understood because it occurred before the introduction of the WWSSN stations and little seismic data are available. Elementary source parameters such as source area, seismic moment and slip distribution have not been well determined.

The source area of an earthquake is often identified as the region containing the aftershocks. The aftershock zone of the 1957 earthquake is the longest of any earthquake ever recorded. It stretches $1200 \mathrm{~km}$ along the Aleutian Trench from approximately $164^{\circ} \mathrm{W}$ to $180^{\circ} \mathrm{W}$ (Figure 1). Both Sykes [1971] and Kanamori [1977] used the $1200 \mathrm{~km}$ long aftershock zone of the 1957 earthquake to estimate seismic moment of $30 \times 10^{20} \mathrm{Nm}$ and $585 \times 10^{20} \mathrm{Nm}$, respectively. However, House et al. [1981] argued that the easternmost end of the aftershock zone near Unalaska Island is anomalous and suggested that this area did not rupture in the 1957 earthquake, leading to the hypothesis that this area is a seismic gap. In any case, using the size of the aftershock zone is an indirect means of deriving the moment.

The moment of the 1957 earthquake has been estimated by more direct methods. Abe [1979] used the relationship between maximum tsunami height and earthquake moment to assign a tsunami magnitude of $M_{t}=9.0$ to the 1957

Copyright 1993 by the American Geophysical Union.

Paper number 93GL01217

0094-8534/93/93GL-01217\$03.00 earthquake. The equivalent moment is $400 \times 10^{20} \mathrm{Nm}$. Ruff $e t$ al. [1985] used the single available surface wave record from Pietermaritzburg, South Africa to estimate the slip distribution and determined a moment of $100 \times 10^{20} \mathrm{Nm}$. However, the response of this instrument is poorly known, making results from this seismic data suspect. Lane and Boyd [1990] have studied the surface wave directivity from this surface wave record by a nonlinear inversion, but they could only determine the rupture length and velocity.

Lack of seismic data has hampered past efforts to determine the source parameters precisely. There is, however, a good quality data set available for this earthquake. The tsunami generated by the earthquake was recorded on tide gauges all around the Pacific Ocean. The tsunami waveforms can be used to determine the source parameters of the 1957 earthquake, which will determine if the Unalaska Island area is a seismic gap.

\section{Computation of Tsunami Propagation}

Tsunamis generated by large earthquakes can be treated as a linear long wave because the wavelength is much greater than the water depth. The wave equation for the small amplitude, linear long wave is

$$
\nabla^{2} h=\frac{1}{c^{2}} \frac{\partial^{2} h}{\partial t^{2}}
$$

where $c=\sqrt{g d}, h$ is the water height, $g$ is the acceleration of gravity, and $d$ is water depth. Equivalently, the equation of motion and the equation of continuity are

$$
\begin{gathered}
\partial Q / \partial t=-g d \nabla h \\
\partial h / \partial t=-\nabla \cdot Q
\end{gathered}
$$

where $\boldsymbol{Q}$ is the flow rate vector.

Given an initial condition, or water height, the equations of

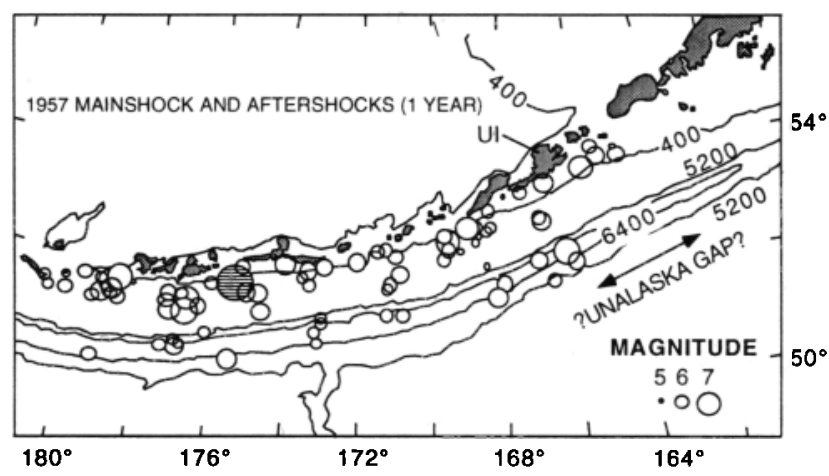

Fig. 1: Detailed plot of the 1957 main shock and aftershock over a period of 1 year. Only events assigned a magnitude of 5 or larger are plotted. The 1957 main shock is shaded and is plotted with a symbol appropriate for its surface wave magnitude $\left(\mathrm{M}_{\mathrm{S}}\right)$ of 8.1. UI indicates the location of Unalaska Island. Bathymetry is in meters. [from House et al., 1981] 
motion and continuity can be solved by finite-difference method on a staggered grid system. Using highly accurate, digital bathymetry of the Pacific Ocean, the tsunami velocity and thus tsunami propagation can be calculated very accurately. The more accurate the bathymetry, the more accurate the computation. This suggests the adoption of a fine grid system for calculating the tsunami propagation. However, very fine grid-spacing on the entire northern Pacific Basin would be impractical due to the enormous computational effort. For the majority of the deep Pacific Ocean where the bathymetry changes slowly, the grid space need not be any finer than $5^{\prime}$ (approximately $10 \mathrm{~km}$ ). However, near coastal areas, the bathymetry changes much more rapidly. Also, islands and harbors where tide gauges are located cannot be adequately represented by 5 ' grid spacing. Therefore, in coastal areas such as the west coast of $\mathbf{N}$. America, the Hawaiian Islands, and around the tide gauges in Alaska, 1' (less than $2 \mathrm{~km}$ ) grid spacing is used.

\section{Tsunami Waveform Inversion}

The method for inverting tsunami waveforms has been used previously by Satake [1989] for local and regional tsunami data. While this study is the first to determine slip distribution from far-field tsunami waveforms, the method is the same.

The fault area is divided into subfaults. The latitude, longitude, strike, dip, depth, and area of each subfault is specified. The vertical deformation of the seafloor from unit displacement on each subfault is calculated (e.g. Okada [1985]). This bottom deformation is then used as the initial condition for the water height, and a synthetic waveform is calculated at each tide gauge for each subfault. These waveforms are the Green's functions for each tide gauge. The observed waveform is a linear superposition of the Green's functions, so the displacement on each subfault can be letermined by solving the linear equation

$$
A_{i j} \cdot x_{j}=b_{i}
$$

where $A_{i j}$ is the computed Green's function at tide gauge $i$ for unit slip on subfault $j, b_{i}$ is the observation at tide gauge $i$, and $x_{j}$ is the unknown slip on subfault $j$. This equation can be solved by least-squares method by minimizing the misfit between the observed and synthetic waveforms.

We divided the aftershock zone of the 1957 earthquake into eleven subfaults. The fault length $(100 \mathrm{~km})$, width $(150$ $\mathrm{km})$, dip angle $\left(15^{\circ}\right)$, and depth to the top of the fault $(1 \mathrm{~km})$ are the same for all of the subfaults. Figure 3 shows the location of the subfaults in relation to the Aleutian Arc. Each subfault has unit displacement in the direction of Pacific Plate motion relative to $N$. America. The slip angle was determined for each subfault individually from the Euler pole at $48.7^{\circ} \mathrm{N},-78.2^{\circ} \mathrm{E}$ with rotation rate of $0.78 \mathrm{deg}-\mathrm{m} . \mathrm{y} \mathrm{-}^{-1}$ [DeMets et al., 1990]. This means that the slip changes from pure dip-slip in the eastern end of the rupture zone to nearly equal components of dip-slip and strike-slip in the west. The synthetic tsunami waveform, or Green's function, was then computed for each subfault.

We inverted the waveforms from 12 tide gauges from Alaska, the Aleutians, Hawaii, and N. America. These tide gauges are Attu, Unalaska, and Yakutat, AK; Neah Bay, WA; San Francisco, Alameda, San Pedro, Los Angeles Harbor,
Newport Bay, and San Diego, CA; and Hilo, HI. The waveform data at each tide gauge station consists of an average of 110 time points with a sampling rate of $1 \mathrm{~min}$, and the total number of data points is 1312. Figure 2 shows the observed and computed waveforms from some of these tide gauges. We performed both a least-squares inversion and an inversion with a positivity constraint.

\section{Slip Distribution}

The slip distribution from the solution with a positivity constraint can be seen in Figure 3 and Table 1. It shows that slip is concentrated in the western half of the aftershock zone from $174^{\circ} \mathrm{W}$ to $180^{\circ} \mathrm{W}$. The largest slip occurred on subfault $4(7 \mathrm{~m})$ and subfault $5(5 \mathrm{~m})$ between $174^{\circ}$ and $177^{\circ} \mathrm{W}$. There is very little slip in the eastern half of the aftershock zone, with subfault 8 having the only appreciable slip. There is no slip in subfaults 9-11 (aside from negligible slip on subfault 11) from $164^{\circ}$ to $169^{\circ} \mathrm{W}$. The results for the free inversion are similar to the constrained solution.

While the computed waveforms for the above solution explain the overall features of the observed waveforms, a careful examination of Figure 2 reveals that the first large positive pulse at Unalaska and at San Francisco are poorly matched. A large displacement on subfault 8 can match the pulse at Unalaska, and a large displacement on subfault 9 can match the first pulse at San Francisco. However, large displacements in either of these subfaults is incompatible with the large amplitude wave at Hilo. We hypothesized from an examination of first arrival times at the three tide gauges in question that a large displacement on a subfault of smaller area and at the down-dip edge of subfault 8 or 9 might be compatible with all three waveforms. Accordingly, we divided subfaults 8 and 9 into smaller faults. Figure 4 shows the position of the additional subfaults 12 and 13 . These subfaults have parameters: length $50 \mathrm{~km}$, width $75 \mathrm{~km}$, dip angle $15^{\circ}$, and depth to the top of fault $20.4 \mathrm{~km}$. Green's functions were computed for these additional faults, and the inversion was performed again. The results are listed in Table 2. Figure 5 shows that a displacement of $3.3 \mathrm{~m}$ on subfault 12 matches the first pulse on the Unalaska waveform and is still compatible with the Hilo waveform. However, the first pulse on the San Francisco waveform is still poorly matched. The solution for 13 subfaults is compatible with our hypothesis of concentration of slip on a smaller subfault in the eastern half

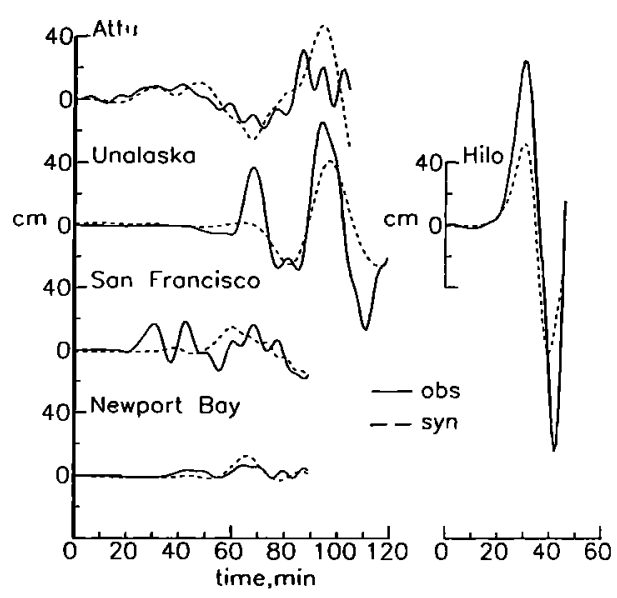

Fig. 2: Observed and synthetic waveforms from inversion for eleven subfaults. Start time of each waveform is different. 


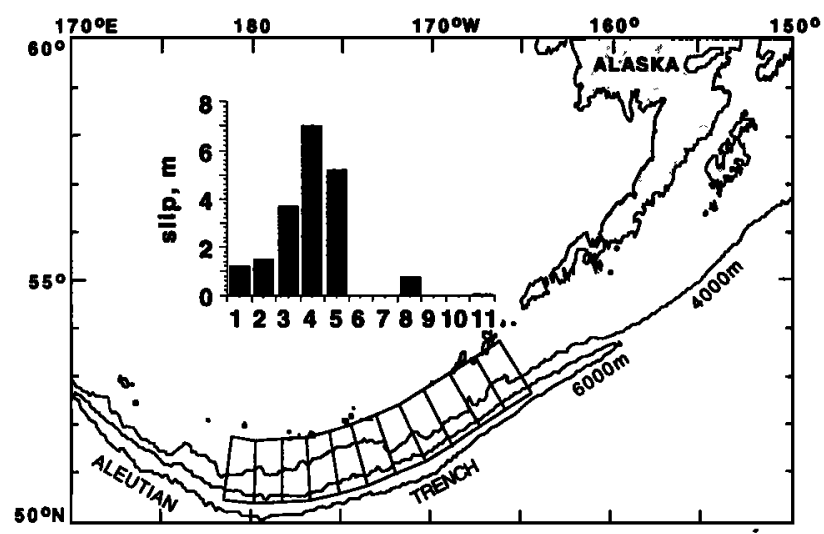

Fig. 3: Slip distribution of 1957 earthquake from inversion for eleven subfaults. The numbered segments correspond to the subfault immediately below.

Table 1: Inversion results for 11 subfaults

\begin{tabular}{lll}
\hline subfault \# & slip, m & error, m \\
\hline 1 & 1.1 & 1.45 \\
2 & 1.5 & 0.36 \\
3 & 3.7 & 1.95 \\
4 & 7.0 & 0.30 \\
5 & 5.2 & 2.11 \\
6 & 0.0 & 0.00 \\
7 & 0.0 & 0.56 \\
8 & 0.76 & 0.66 \\
9 & 0.0 & 0.00 \\
10 & 0.0 & 0.00 \\
11 & 0.08 & 0.16 \\
\hline RMS error, m & .1002 \\
average slip, m & 1.77 \\
Mo, 1020 Nm & 87.6 \\
\hline
\end{tabular}

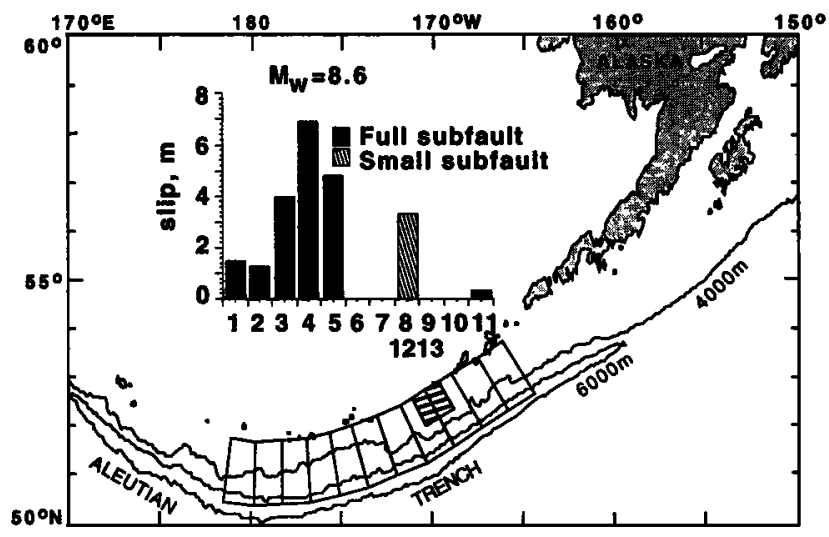

Fig. 4: Slip distribution of 1957 earthquake from inversion for thirteen subfaults. The numbered segments correspond to the subfault immediately below. Subfaults 12 and 13 are shaded.

of the rupture zone. It is also compatible with the total average slip for the entire rupture zone, as the slip on subfault 12 is approximately four times the slip on subfault 8 from the solution for eleven subfaults.

It is interesting to note that a portion of the 1957 rupture zone reruptured in the Andreanof Islands region in May 1986. This area, from about $172^{\circ}-177^{\circ} \mathrm{W}$, is approximately the same region in which we determined the greatest slip for the 1957 earthquake. This perhaps confirms the existence of a large asperity in this region [Hwang and Kanamori, 1986, Houston and Engdahl, 1989].

\section{Error Estimates}

The formal statistical errors for a standard least-squares inversion cannot always be considered a good estimate of the actual errors [Tichelaar and Ruff, 1989]. Further no formal errors can be estimated for a non-negative least-squares inversion. Therefore, we applied a resampling technique to determine the errors. This technique is jackknifing, in which a fixed number of random data points are deleted to produce a resample that is then inverted for the model parameters. If we treat each waveform as 110 data points out of a total of 1312 data points, then we can make a delete- 110 jackknife with corresponding errors by reinverting the tsunami waveforms twelve times, each time dropping a different waveform. However, since we delete an entire waveform at a time, rather than 110 random data points, the errors determined can be strongly influenced by the presence or absence of certain waveforms. Therefore, we examined each of the jackknife inversions and determined that two waveforms, from Hilo and Attu, were necessary to obtain a stable solution. We recomputed the errors using only those jackknifes that included both Hilo and Attu.

The errors are given in Tables 1 and 2. These error estimates show that the slip distribution is significantly nonzero for all the subfaults except for: subfault 1 and 8 in the inversion for 11 subfaults; and subfault 1 in the inversion for 13 subfaults. These error estimates show that the concentration of slip in the western half of the aftershock zone and the small slip in the eastern half are real.

\section{Discussion}

As stated in the introduction, previous estimates of the seismic moment in the 1957 earthquake vary by as much as an order of magnitude. With slip distribution as determined by tsunami waveforms, the seismic moment can now be accurately estimated. The two estimates of the moment are $88 \times 10^{20} \mathrm{Nm}$ and $84 \times 10^{20} \mathrm{Nm}$. These estimates give a moment magnitude of $M_{w}=8.6$. This is much smaller than the

Table 2: Inversion results for 13 subfaults

\begin{tabular}{lll}
\hline subfault \# & slip, m & error, m \\
\hline 1 & 1.5 & 1.35 \\
2 & 1.3 & 0.26 \\
3 & 4.0 & 1.75 \\
4 & 6.9 & 0.20 \\
5 & 4.8 & 1.98 \\
6 & 0.0 & 0.00 \\
7 & 0.0 & 0.00 \\
8 & 0.0 & 0.00 \\
9 & 0.0 & 0.00 \\
10 & 0.0 & 0.00 \\
11 & 0.32 & 0.66 \\
12 & 3.3 & 0.59 \\
13 & 0.0 & 0.13 \\
\hline RMS error, m & .0975 \\
average slip, m & 1.70 \\
Mo, 1020 Nm & 84.2 \\
\hline
\end{tabular}




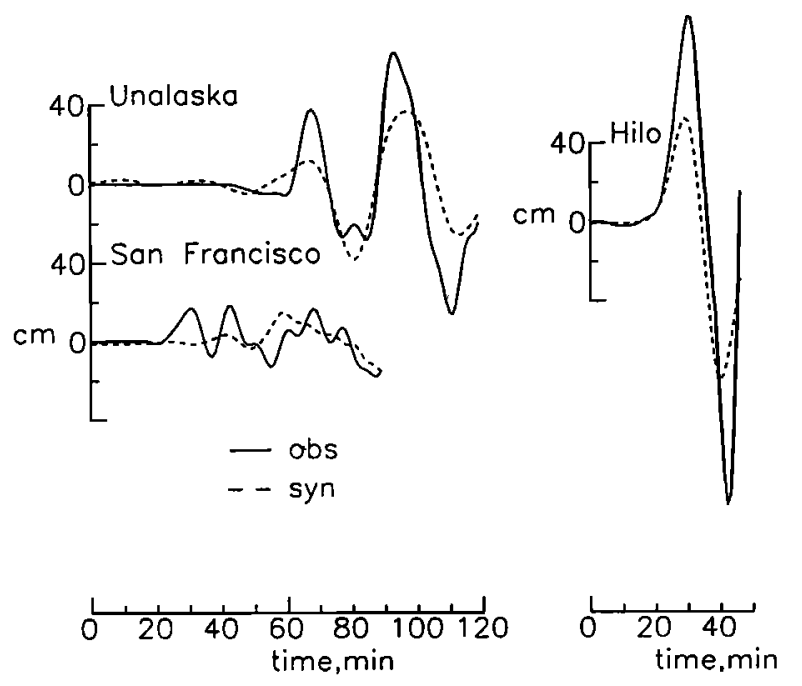

Fig. 5: Observed and synthetic waveforms from inversion for thirteen subfaults. Start time for each waveform is different.

estimate of $M_{w}=9.1$ originally assigned by Kanamori [1977]. However, this estimate is in good agreement with the later estimate of $100 \times 10^{20} \mathrm{Nm}$ by Ruff et al. [1985], which was determined from the surface wave record. Ruff $e t$ al. also determined the moment distribution. It shows that the greatest moment release occurred in the western half of the aftershock zone and that little moment was released in the eastern half. Again this is similar to our results. It should be noted, however, that Boyd et al. [1992] have speculated from the aftershock sequence that moment release was concentrated in the eastern section of the aftershock zone from $167^{\circ}$ to $175^{\circ} \mathrm{W}$ rather than in the western section. However, this hypothesis is based only on the pre- and postearthquake seismicity. Finally, our determination of the source area and slip distribution have shown that the easternmost end of the aftershock zone did not rupture in the 1957 event, making the Unalaska Island area a seismic gap.

Acknowledgments. We are indebted to Larry Ruff and Yuichiro Tanioka for many helpful discussions and suggestions. This work was supported by U.S. Geological Survey grant 1434-92-G-2187. This work was partially supported by NSF grant EAR920000N and utilized the Cray2 system at the National Center for Supercomputing Applications, University of Illinois at Urbana-Champaign.

\section{References}

Abe, K., Size of great earthquakes of 1873-1974 inferred from tsunami data , J. Geophys. Res., 84, 1561-1568, 1979.

Boyd, T.M., E.R. Engdahl, and W. Spence, Analysis of seismicity associated with a complete seismic cycle along the Aleutian Arc: 1957-1989, in Wadati Conference on Great Subduction Earthquakes, Sept. 16-19, University of Alaska (43-50 in extended abstracts), 1992.

DeMets, C., R.G. Gordon, D.F. Argus, and S. Stein, Current plate motions, Geophys. J. Int., 101, 425-478, 1990.

House, L.S., L.R. Sykes, J.N. Davies, and K.H. Jacob, Identification of a possible seismic gap near Unalaska island, eastern Aleutians, Alaska, in Earthquake Prediction - An Intermational Review, edited by D. W. Simpson and P. G. Richards, 81-92, American Geophysical Union, 1981.

Houston, H., and E.R. Engdahl, A comparison of the spatiotemporal distribution of moment release for the 1986 Andreanof Islands earthquake with relocated seismicity, Geophys. Res. Lett., 16, 1421-1424, 1989.

Hwang, L.J., and H. Kanamori, Of the May 7, 1986 Andreanof islands earthquake source parameters, Geophys. Res. Lett., 13, 1426-1429, 1986.

Kanamori, H., The energy release in great earthquakes, $J$. Geophys. Res., 82, 2981-2987, 1977.

Lane, F.D., and T.M. Boyd, A simulated annealing approach to the inversion of surface wave directivities, EOS, 71 , 1468, 1990.

Okada, Y., Surface deformation due to shear and tensile faults in a half-space, Bull. Seism. Soc. Am., 75, 1135$1154,1985$.

Ruff, L., H. Kanamori, and L.R. Sykes, The 1957 great Aleutian earthquake, EOS, 66, 298, 1985.

Satake, K., Inversion of tsunami waveforms for the estimation of heterogeneous fault motion of large submarine earthquakes: the 1968 Tokachi-oki and the 1983 Japan Sea earthquakes, J. Geophys. Res., 94, 56275636, 1989.

Sykes, L., Aftershock zones of great earthquakes, seismicity gaps, and earthquake predicion for Alaska and the Aleutians, J. Geophys. Res., 76, 8021-8041, 1971.

Tichelaar, B. W., and L. J. Ruff, How good are our best models? Jackknifing, bootstrapping, and earthquake depth, EOS, 70, 593,605-606, 1989.

J.M. Johnson and K. Satake, Dept. of Geological Sciences, Univ. of Michigan, Ann Arbor, MI 48109-1063.

Received: February 18, 1993

Accepted: May 3, 1993 